\title{
A problematização da Vida em Michel Foucault, Roberto Esposito e Nikolas Rose
}

\author{
Gislene Almeida \\ Universidade do Estado da Bahia \\ Universidade Nova de Lisboa \\ (Brasil) \\ gislla@yahoo.com
}

Recibido $17 / 06 / 2018$

Aprobado 19/07/2018

\section{Resumo}

As investigações de Michel Foucault acerca do exercício do poder sobre a vida inspiraram, tanto em termos de objetivos -uma genealogia dos processos de subjetivação do homem moderno - quanto em termos metodológicos - arqueologia das formas de resistência à sujeição - inumeráveis estudos, polêmicas, críticas e malentendidos, com muitos dos quais Foucault chegou a dialogar ainda em vida. Talvez os conceitos mais presentes nessas investigações sejam os de biopolítica e bio-poder, formulados por Foucault no bojo da problematização que envolve as relações entre saber, poder e subjetividade. O conceito de biopolítica pode ser entendido, grosso modo, como uma "gestão calculista da vida" em prol da promoção da vida, com o menor dispêndio possível tanto econômico quanto ideológico, institucional, etc. $\mathrm{O}$ presente artigo visa a apresentar, ainda que sumariamente, o lugar ocupado pelas análises destes conceitos no interior da obra foucaultiana, para, a seguir, apontarmos duas dessas contribuições teóricas que estão em curso neste início de século XXI e que dialogam diretamente com o pensamento foucaultiano: o conceito de paradigma imunitário, de Roberto Esposito, e o conceito de ética somática, de Nikolas Rose.

Palavras-chave: biopolítica, paradigma imunitário, bioeconomia, ética somática 


\section{Abstract}

Michel Foucault's investigations of the exercise of power over life have inspired, both in terms of objectives - a genealogy of modern man's subjectivation processes - and in methodological terms - archeology of forms of resistance to subjection -, innumerable studies, polemics, criticisms and misunderstandings, with many of whom Foucault came to dialogue while still alive. Perhaps the most present concepts in these investigations are those of biopolitics and bio-power, formulated by Foucault in the bosom of the problematization that involves the relations between knowledge, power and subjectivity. The concept of biopolitics can be roughly understood as a "calculative management of life" for the promotion of life, with the least possible expenditure: economic, ideological, institutional, and so on. The present article aims to present, although summarily, the place occupied by the analysis of these concepts within Foucault's work, and then to point out two of these theoretical contributions that are underway at the beginning of the twenty-first century and that dialogue directly with the Foucauldian thinking: the concept of immunity paradigm, by Roberto Esposito, and the concept of somatic ethics, by Nikolas Rose.

Key words: biopolitics, immunity paradigm, bioeconomics, somatic ethics

\section{Introdução}

No presente artigo focalizaremos a contribuição de Michel Foucault para o discurso contemporâneo acerca do exercício do poder sobre a vida, bem como acerca da ideia de poder da vida. Na primeira abordagem, a do exercício do poder sobre a vida, Foucault analisa duas dimensões ou perspectivas, quais sejam: o controle sobre os corpos individuais, e a regulamentação ou normalização da vida humana enquanto espécie animal. Na segunda abordagem, a do exercício do poder da vida, tentaremos entrever uma ontologia da vida, e nos perguntamos se a mesma coincidiria com uma ontologia de nós mesmos, no sentido da investigação acerca das formas pelas quais nós, ocidentais, nos tornamos historicamente sujeitos éticos. A ideia de vida é tomada aqui enquanto pólo de resistência, ou, conforme a assertiva deleuziana, a "capacidade 
de resistir da força” ${ }^{1}$. Ambas abordagens, que não são estanques, ou sem ressonância mútua, tomam a ideia de poder não enquanto substância, mas sim enquanto foco de experiência "microfísica", ou mais precisamente enquanto algo que se exerce de maneira relacional, e não necessariamente sob a forma da repressão, de modo que Foucault, ao longo do seu percurso histórico filosófico, encontra uma complexa e estreita relação entre estratégias de poder (política), estratos de saber (ciência) e o que ele chama de técnicas de si., caracterizadas como práticas através das quais os indivíduos exercem a sua liberdade (ética).

A partir daí, apontaremos a seguir algumas derivações interpretativas que giram em torno das pesquisas foucaultianas acerca do problema do exercício do poder sobre a vida e do exercício do poder da vida neste alvorecer do século XXI, as quais atentam para importantes mudanças ocorridas nas sociedades ocidentais nos últimos vinte anos, sobretudo as resultantes dos cruzamentos entre os avanços na biotecnologia e na biomedicina na configuração de um novo conceito de vida. A este propósito, destacamos os conceitos de paradigma imunitário, em Roberto Esposito ${ }^{2}$ e o conceito de ética somática, em Nikolas Rose $^{3}$, por constituírem dois enfoques distintos acerca da configuração da biopolítica e do biopoder nas sociedades ocidentais, favorecendo assim, a uma só vez, a ampliação de perspectivas para pensarmos tais temas, e a revisitação à "caixa de ferramentas" fornecida pelos conceitos foucaultianos os quais podem, sem dúvida, auxiliar-nos a esculpir a atualidade, ainda que por vezes a golpes de martelo. Começaremos, pois, por situar o lugar que as ideias de biopolítica e biopoder ocupam no interior da obra foucaultiana.

\section{Processos de subjetivação, biopolítica e biopoder}

Como dito acima, Foucault objetiva, em toda a trajetória do seu pensamento, oferecer-nos uma genealogia dos processos de subjetivação, ou, na expressão de

\footnotetext{
${ }^{1}$ DELEUZE, Gilles. Foucault. Trad. José Carlos Rodrigues. Lisboa: Vega(s/d). p. 125.

${ }^{2}$ ESPOSITO, Roberto. Bíos: biopolítica e filosofia. Edições 70. 2010.

${ }^{3}$ ROSE, Nikolas. A Política da própria vida: biomedicina, poder e subjetividade no século XXI. São Paulo: Paulus, 2013.
} 
Dreyfus \& Rabinow ${ }^{4}$, uma "genealogia do indivíduo moderno como objeto". Esta genealogia compreende três domínios:

Primeiro, a ontologia histórica de nós mesmos em relação à verdade, na qual nós nos constituímos como sujeitos do conhecimento; [segundo,] a ontologia histórica em relação ao poder, onde nos constituímos como sujeitos agindo sobre os outros; terceiro, a ontologia histórica em relação à ética, onde nos constituímos como sujeitos de nossa própria ação moral.."

Os dois primeiros domínios remetem à análise das práticas de objetivação do ser humano, ou, se se preferir às técnicas de sujeição, ao passo que o último remete à análise das técnicas de si, ou, se se preferir, das práticas de liberdade, ou ainda, da constituição de uma estética da existência (ethopoiésis). Foucault estabelece uma profunda ligação entre as "três ontologias" acima apontadas, de tal sorte que é impossível falar de uma, sem falar das outras duas. Nesse sentido, no que tange à relação entre subjetividade, verdade e poder, Foucault atenta, desde os seus primeiros escritos, para a paulatina assunção, que se estende desde o sujeito cartesiano até ao advento das ciências humanas, no século XVIII, da ciência como protagonista de um novo regime de verdade, cujo crivo de legitimação é a clareza e a distinção das representações, entendendo aqui regime de verdade como aquilo que determina as condições de possibilidade do discurso verdadeiro e as condições de possibilidade do próprio objeto desse discurso. Acontece que, ao constituir-se como sujeito de conhecimento, o homem moderno constitui-se, ao mesmo tempo, como objeto de conhecimento. Ora, como veremos um pouco melhor mais adiante, em $A$ vontade de saber Foucault demonstra que esse novo regime de verdade está intimamente relacionado às transformações históricas no que tange ao desenvolvimento de uma

\footnotetext{
${ }^{4}$ DREYFUS, Hubert. \& RABINOW, Paul. Michel Foucault: uma trajetória filosófica para além do estruturalismo e da hermenêutica. Trad. Vera Portocarrero. Rio de Janeiro: Forense Universitária. 1995. p. 158.

${ }^{5}$ FOUCAULT, Michel. Qu'est-ce que la critique? suivi de La culture de soi. Paris: Vrin. 2015. p.102-103.
} 
nova razão de Estado: enquanto a racionalidade do antigo regime ancorava-se no direito do soberano de "fazer morrer ou de deixar viver", onde o indivíduo "existia" apenas na medida em que afetava a pessoa do soberano, ameaçando perturbar a sua legitimidade, sendo, portanto, "merecedor" de morte, ou quando o indivíduo era convocado para defender o soberano de uma ameaça externa, ou seja, o poder exercido pelo soberano repercutia nos indivíduos sob a forma jurídica do imposto, "mecanismo de subtração, direito de apropriar de uma parte das riquezas, da extorsão de produtos, de bens, de serviços, de trabalho e de sangue, imposta aos súditos." ${ }^{6}$, na nova racionalidade de Estado que se vê surgindo a partir do final do século XVII, e que, como dissemos, é fortemente marcada por alguns acontecimentos históricos não necessariamente ligados ao Estado, tais como, as necessidades de ampliação do mercado, em grande parte graças às explorações coloniais, o qual demanda o fortalecimento das forças produtivas, e aí surge, paralelamente, o crescimento da população das cidades, demandando o desenvolvimento de novas formas de distribuição dos indivíduos no espaço urbano, condições de habitação, métodos sanitários (entre os quais cuidados com o ar das cidades, com a higiene individual e coletiva, busca de erradicação ou controle de doenças não-fatais, mas contagiosas), etc., novas estratégias são requeridas, uma vez que

O "imposto" tende a não ser já a forma principal, mas apenas uma peça no meio de outras que têm funções de incitamento de reforço, de controlo, de vigilância, de crescimento e de organização das forças que submete: um poder destinado a produzir forças, a fazê-las crescer e a ordená-las, mais do que votado a vedá-las, a submetê-las ou a destruí-las. O direito de morte tenderá desde logo a deslocar-se, ou pelo menos a apoiar-se, em exigências de um poder que gere a vida, e a ordenar-se ao que elas reclamam. ${ }^{7}$

\footnotetext{
${ }^{6}$ FOUCAULT, Michel. História da sexualidade I: A vontade de saber. Trad. Pedro Tamen. Lisboa: Relógio D’água. 1994. p. 138, itálico nosso.

${ }^{7}$ FOUCAULT, Michel. História da sexualidade I: A vontade de saber. Op. cit. pp. 138-139, itálicos nossos.
} 
É assim que, diante dessa nova racionalidade de Estado, inicialmente, em $A$ vontade de saber, Foucault constata que "ao velho direito de fazer morrer ou de deixar viver se substitui um poder de "fazer viver ou de rejeitar para a morte" ${ }^{8}$ e no mesmo ano de publicação de $A$ vontade de saber, no curso intitulado Em defesa da sociedade, em sua última aula, de 17 de março de 1976, Foucault amplia sua perspectiva, ao afirmar que o direito político do século XIX

consistiu, não digo exatamente em substituir, mas em completar esse direito de soberania - fazer morrer ou deixar viver - com outro direito novo, que não vai apagar o primeiro, mas vai penetrá-lo, perpassá-lo, modificá-lo, e que vai ser um direito, ou melhor, um poder exatamente inverso: poder de "fazer" viver e de "deixar" morrer. ${ }^{9}$

Tomando por encargo gerir a vida o Estado transforma-se em bio-poder por duas formas, ou dois pólos: um, atuando sobre os corpos individuais, toma por função garantir "o seu adestramento, o crescimento das suas aptidões, a extorsão das suas forças, o crescimento paralelo da sua utilidade e da sua docilidade, a sua integração em sistemas de controlo eficazes e econômicos." ${ }^{10}$. É o pólo que Foucault denomina por anátomo-política, cujos dispositivos ${ }^{11}$ são regidos por técnicas disciplinares. 0

\footnotetext{
${ }^{8}$ FOUCAULT, Michel. História da sexualidade I: A vontade de saber. Op. cit. p. 140.

${ }^{9}$ FOUCAULT, Michel. Em defesa da sociedade. Trad. Maria Ermantina Galvão. São Paulo: Martins Fontes. 1999. p. 287

${ }^{10}$ FOUCAULT, Michel. História da sexualidade I: A vontade de saber. Op. cit. p. 141 (itálico nosso).

11 “O termo 'dispositivo' apareceria em Foucault nos anos 1970 e designa inicialmente os operadores materiais do poder, ou seja, as técnicas, as estratégias e as formas de assujeitamento posta em cena pelo poder. A partir do momento em que a análise foucaultiana se concentra sobre a questão do poder, o filósofo insiste sobre a importância de se ocupar não 'do edifício jurídico da soberania, ao lado dos aparelhos de Estado e ao lado das ideologias que o acompanham', porém dos mecanismos de dominação: é esta a escolha metodológica que engendra a utilização da noção de 'dispositivos'. Estes são, por definição, de natureza heterogênea: trata-se tanto de discursos quanto de práticas, de instituições quanto de táticas moventes: é assim que Foucault chega a falar, segundo o caso, de
} 
outro pólo, que, sempre de acordo com Foucault, caracteriza-se pela administração do corpo humano enquanto espécie, vai formar-se a partir de meados do século XVIII, e, conforme já observamos acima, vem para complementar e para aliar-se às técnicas de controle dos corpos individuais, tomando por função regular os processos biológicos, de modo que a vida da população não esteja mais exposta aos caprichos da natureza no que tange à natalidade, à mortalidade, à saúde, à velhice, etc. A este pólo Foucault denomina biopolítica. Entretanto, ainda acerca desses novos dispositivos de saberpoder, Foucault insiste em desviar-se da interpretação freudo-marxista, cuja análise do poder está circunscrita aos discursos ideológicos e às práticas coercitivas no interior dos aparelhos do Estado (escola, família, Igreja), optando por "analisar as relações do [sic] poder por meio do enfrentamento das estratégias ${ }^{12}$, ou seja, na poeira do embate agonístico das relações de poder locais e empíricas: é a ideia de uma microfísica do poder, entendendo que este não é exercido apenas pelo Estado, mas também nas relações entre patrões e empregados, entre marido e esposa, pais e filhos, professor e aluno, etc., ou seja, onde existe sociabilidade, existem relações de poder. Seguindo as pegadas de Nietzsche, para Foucault o poder não é uma substância, algo que se pode ter ou não ter, algo que um indivíduo ou um grupo de indivíduos pode tomar do outro, nem tampouco uma capacidade de aceder ou dispor de "coisas", mas sim uma relação de forças formadas, necessariamente, por dois pólos, um cujo extremo é o estado de dominação totalitária e outro que oscila entre sujeição e resistência, ambos compostos por uma infinita série de variações táticas que percorrem a distância entre um e outro. Além disso, o discurso marxista permanece sempre portador de uma visão teleológica da história, na medida em que opõe o discurso ideológico da classe dominante (por definição, falso) ao discurso da classe proletária (verdadeiro), sendo este último, por força de uma espécie de justiça histórica vinda de alhures, destinado a ascender ao poder quando o seu discurso 'dispositivos de poder', 'dispositivos de saber', dispositivos disciplinares', “dispositivos de sexualidade', etc." (REVEL, Judith. Diccionnaire Foucault. Paris: Ellipses 2008. p. 41).

${ }^{12}$ FOUCAULT, Michel. O sujeito e o poder. In: MOTTA, M. (Org.). Ditos e escritos, Vol. IX: Genealogia da ética, subjetividade e sexualidade. Trad. Abner Chiquieri. Rio de Janeiro: Forense Universitária. 2014. p. 121. 
tornar-se dominante. Ora, primeiramente, da ideia marxista de luta de classes, Foucault atém-se mais à ideia de luta, que à de classe. Segundo, Foucault desconstrói, também assumidamente influenciado por Nietzsche, a ideia de verdade transcendental, objetiva, por assim dizer, sempre sublinhando que, para a análise das relações de poder, o que importa são os "efeitos de verdade", sendo desnecessário reiterar que estes efeitos não são atemporais e menos ainda universais, mas históricos.

\begin{abstract}
A verdade não existe fora do poder ou sem poder (não é - não obstante um mito, de que seria necessário esclarecer a história e as funções - a recompensa dos espíritos livres, o filho das longas solidões, o privilégio daqueles que souberam se libertar). A verdade é deste mundo; ela é produzida nele graças a múltiplas coerções e nele produz efeitos regulamentados de poder. Cada sociedade tem seu regime de verdade, sua "política geral" de verdade: isto é, os tipos de discurso que ela acolhe e faz funcionar como verdadeiros; os mecanismos e as instâncias que permitem distinguir os enunciados verdadeiros dos falsos, a maneira como se sanciona uns e outros; as técnicas e os procedimentos que são valorizados para a obtenção da verdade; o estatuto daqueles que têm o encargo de dizer o que funciona como verdadeiro. ${ }^{13}$
\end{abstract}

Assim Foucault conclui que, para empreender uma análise dos processos de constituição do sujeito moderno, é preciso empreender uma genealogia do poder e uma genealogia da verdade cujo método, ao tempo em que abandona o modelo da historiografia monumental como fonte de pesquisa, assume como tarefa limpar a poeira dos arquivos, pois só assim se poderá ver subir a poeira oriunda das lutas travadas pelos pólos de resistência à sujeição: trata-se de orientar-se pelo que ele denomina método arqueológico.

\footnotetext{
${ }^{13}$ FOUCAULT, Michel. Verdade e poder. In: MACHADO, R. (Org. e Trad.). Microfísica do poder. Rio de Janeiro: Edições Graal. 1979. p. 12.
} 
A partir daí, Foucault observa a formação de novas condições de possibilidade do discurso, pois que, como já aludimos acima, surge um novo objeto para o discurso (ou seja, um problema), que, doravante, coincide com o objeto do poder estatal que é, justamente, a vida da população. É pela introdução refletida de estratégias de podersaber aplicadas diretamente à vida dos indivíduos e das populações que se iniciam os processos de subjetivação característicos da modernidade. E é sobretudo a isto que Foucault se refere quando fala de biopolítica: "o homem, durante milênios, permaneceu o que era para Aristóteles: um animal vivo e, além disso, capaz de uma existência política; o homem moderno é um animal na política do qual a sua vida de ser vivo está em causa." ${ }^{14}$.

Em seu curso de 1978-1979, intitulado O Nascimento da biopolítica, Foucault destaca a importância da economia política para o desenvolvimento do mercantilismo entendido como forma de governo, e não como doutrina econômica ${ }^{15}$. A economia política aparece justamente como "o instrumento intelectual de autolimitação da nova razão governamental” ${ }^{\prime 16}$, e este limite, por força da natureza, passa a ser ditado pelo mercado $^{17}$. Nesse sentido, a economia política constitui o campo do saber que instaura um novo regime de verdade, cujo pressuposto é de que, para governar bem é preciso conhecer os efeitos da ação governamental, o que permitiria calcular a ação governamental por meio de proposições passíveis de serem classificadas como

\footnotetext{
${ }^{14}$ FOUCAULT, Michel. História da sexualidade I: A vontade de saber. Op. cit. p. 145.

15 “O mercantilismo não é uma doutrina econômica, é muito mais que isso (...). É uma determinada organização da produção e dos circuitos comerciais segundo o princípio de que, em primeiro lugar, o Estado deve enriquecer pela acumulação monetária, em segundo, deve reforçar-se pelo aumento da população, em terceiro, deve estar e manter-se num estado de concorrência permanente com as potências estrangeiras." (FOUCAULT, Michel. O nascimento da biopolítica. Trad. Pedro Elói Duarte. Lisboa: Edições 70. 2010, p. 29).

${ }^{16}$ FOUCAULT, Michel. O nascimento da biopolítica. Op. cit., p. 38.

17 “Deste modo, por exemplo, é uma lei da natureza, explicarão os economistas, que a população, por exemplo, passe para os salários mais elevados; é uma lei da natureza que determinada tarifa alfandegária, protetora dos altos preços dos alimentos, provoque fatalmente algo como a penúria." (FOUCAULT, Michel. O nascimento da biopolítica. Op. cit., p. 41).
} 
verdadeiras ou falsas ${ }^{18}$ : daí surgem a estatística, a antropologia social, a medicina social, a sociologia, a psiquiatria, etc. Há que uniformizar a população, normalizá-la, estagná-la ao máximo, ou ao menos o suficiente para torná-la "cognoscível", eliminar ao máximo a margem de imprevisibilidade no comportamento do indivíduo e do corpo social, uma vez que o critério de avaliação da ação governamental passa a ser o êxito ou o fracasso (relativo à ampliação das forças produtivas), e não a legitimidade ou ilegitimidade dos seus procedimentos.

Onde a vida biológica ganha um sobrevalor, a sua perda passa a ser o grande mal a ser evitado a qualquer custo. O corpo, em sua dimensão estritamente orgânica, maquínica, é aquilo que, antes de qualquer outro bem, deve ser protegido: é em nome da segurança, da proteção do "interesse coletivo contra os interesses individuais. E vice-versa"19 ${ }^{19}$, que surgem práticas divisórias no campo social, já não mais restritas ao âmbito jurídico da lei, como no antigo regime, onde o soberano decidia quem merecia morrer e quem poderia viver, e o que estava em jogo era a constituição de um sujeito de direito, mas que opera por meio de esquemas dicotômicos de distinção hierárquica, separação, interdição e/ou exclusão dos indivíduos, onde o que está em jogo é a constituição de um sujeito "normal" (práticas que denotam já uma vocação para o racismo que assume o aspecto de uma eugenética cujo expoente mais extremo e mais notável é o nazismo). Assim que a lei vai cada vez mais tomando as feições de norma, de busca por uma padronização, uniformização da vida individual e coletiva, tendo em vista a segurança física e social e a otimização das condições de vida. E eis que surgem alguns "sujeitos-problema", manifestos nas figuras do criminoso ou do perigoso, do vagabundo/desempregado, do anormal, do louco, do doente, do velho, do pervertido, etc., enfim, os "infames" que, dessa vez, não têm o privilégio da atenção do poder estatal apenas para defrontar-se com a morte, mas apresentam-se como alvo principal dos dispositivos reguladores, responsáveis pela demarcação da linha tênue que os separa dos seus respectivos opostos, os passíveis de serem considerados "cidadãos de bem", ou seja, aqueles que, coincidentemente, são passíveis de, na qualidade de seres

\footnotetext{
${ }^{18}$ FOUCAULT, Michel. O nascimento da biopolítica. Op. cit. P. 44.

${ }^{19}$ FOUCAULT, Michel. O nascimento da biopolítica. Op. cit. p. 95.
} 
vivos, desempenharem no espaço social, urbano, populacional, uma conduta, um modo de vida, que sirva de alguma utilidade produtiva, de modo que propicie "o ajustamento da acumulação dos homens à do capital”20.

Um dos paradoxos da biopolítica é que o pólo "das forças que resistem" vão reivindicar justamente essa mesma "vida otimizada" (ainda que no século XIX, e mesmo nos dias de hoje, de maneira um tanto mais difusa, essa reivindicação se dê em termos de direitos, e não nos termos de uma ética, ou, se se preferir, de um "trabalho de si sobre si") que é alvo da nova racionalidade governamental moderna: "o que é reivindicado e serve de objetivo é a vida, entendida como necessidades fundamentais, essência concreta do homem, realização das suas virtualidades, plenitude do possível." ${ }^{21}$. A complicação se dá pelo fato que não existe e podemos dizer que nunca existirá apenas uma forma de vida, por mais que se tente uniformizar, padronizar, agir sobre a ação dos indivíduos. No fundo, talvez, o que se reivindique seja uma espécie de laisser-faire da vida mesma (e não necessariamente da vida física ou psíquica), incluindo aí a exposição a todos os riscos de morte, ou pequenas mortes diárias. Talvez o que se reivindique é que a vida torne-se o que ela é, ou seja, a resistência seria justamente ao aprisionamento da vida à vida: é com esta perspectiva que entendemos Deleuze quando afirma (ou melhor, que assim podemos depreender), que a resistência é a fuga, a criação de linhas de fuga, mais que de estratégias. A resistência não se dá pela luta, tomada no sentido de uma negação, mas sim pela abertura de novas linhas de fuga, que é uma outra forma de pôr fim a uma relação de dominação. Dito de outra maneira: o pólo da resistência não se confundiria com uma espécie de "oposição" ao pólo dominador, mas, antes, estaria muito mais próximo do que Nietzsche designava por "desviar o olhar", por meio da criação de contra-condutas. Em Desejo e prazer", Deleuze afirma que uma das suas poucas divergências com Foucault é que, enquanto este busca entender os processos de subjetivação por meio das estratégias de poder-

\footnotetext{
${ }^{20}$ FOUCAULT, Michel. História da sexualidade I: A vontade de saber. Op. cit. p. 143.

${ }^{21}$ FOUCAULT, Michel. História da sexualidade I: A vontade de saber. Op. cit. p. 147.

${ }^{22}$ DELEUZE, Gilles. Desir et plaisir. In: Magazine Litteraire, n. 325: Foucault aujourd'hui. Trad. Luiz B. Orlandi. 1994.
} 
saber, ele, na sua fidelidade conceitual a Spinoza, entende o poder como "uma afecção do desejo" ${ }^{\prime 23}$, sendo o poder secundário em relação ao desejo. O problema para ele não seria exatamente o de como se exerce o poder, mas o de como é possível desejálo. Antes de uma genealogia do poder, do saber, da moral ou da ética, seria preciso empreender uma analítica do desejo.

Com efeito, se os dispositivos de poder são de alguma maneira constituintes, só pode haver contra eles fenômenos de "resistência", e a questão incide sobre o estatuto desses fenômenos. Sem dúvida, eles serão menos ainda ideológicos e anti-repressivos. (...). Mas qual estatuto vai Ihes dar ele? Há várias direções aqui: 1) Aquela de VS [Vontade de saber](126-127 no original), na qual os fenômenos de resistência seriam como uma imagem invertida dos dispositivos (...). Mas essa direção parece-me bloquear as saídas tanto quanto encontrar uma. 2) A direção apontada na entrevista relativa à função política do intelectual: se os dispositivos de poder são constitutivos de verdade, se há uma verdade do poder, deve haver aí, como contra-estratégia, uma espécie de poder da verdade contra os poderes. Donde, em Michel, o problema do papel do intelectual; donde sua maneira de reintroduzir a categoria de verdade, o que me leva a perguntar o seguinte: renovando completamente essa categoria, ao fazê-la depender do poder, ele encontrará nessa renovação uma matéria retornável contra o poder? Mas aqui não vejo como. É preciso esperar que Michel, no nível de sua microanálise, diga essa nova concepção de verdade. ${ }^{24}$

Sem querer resolver aqui este imbróglio, pudemos observar que toda a análise de Foucault concernente ao exercício do poder sobre a vida e do exercício do poder da vida passa por um mapeamento das estratégias de saber-poder (discursivas ou nãodiscursivas, estatais ou não-estatais), as quais, incessantemente, se retro-alimentam, compõem e decompõem suas infinitas possibilidades de relações. Entretanto, importa

\footnotetext{
${ }^{23}$ DELEUZE, Gilles. Desir et plaisir. Op. cit. p. 18.

${ }^{24}$ DELEUZE, Gilles. Desir et plaisir. Op. cit. p. 20.
} 
não esquecer que esses bio-poderes são regidos não por um poder transcendente, longínquo, mas na materialidade das suas relações: ação sobre ação:

o que define uma relação de poder é o modo de ação que não age direta e imediatamente sobre os outros, mas que age sobre a sua ação própria. Uma ação sobre a ação, sobre ações eventuais, ou atuais, futuras ou presentes." ${ }^{25}$

Dessa maneira, ao perguntar-se acerca de como se desenvolveu o poder sobre a vida nas sociedades ocidentais, Foucault encontra toda uma imbricação entre os diversos procedimentos discursivos e não-discursivos, de estímulos e interdições que não são explicados nem à luz nem da ideologia, a qual partiria de pressupostos transcendentes à história, recaindo num projeto teleológico que transcenderia aos indivíduos, em nome de categorias universalizantes, como a de natureza humana, por exemplo; nem à luz da repressão (por meio da lei e da vigilância). De todas as maneiras, para Foucault, são as estratégias, as táticas de reversão das relações de poder, que vêm a definir o esprit de uma sociedade.

Mas, talvez, o grande paradoxo da biopolítica seja o de que, no limite, a mesma adquire o efeito oposto ao inicialmente "desejado". É o problema da tanapolítica (política de morte). É sobre este paradoxo, ou, ao menos, sobre os enfoques dados a este paradoxo, que invocaremos os conceitos de paradigma imunitário, de Roberto Esposito, e ética somática, de Nikolas Rose.

\section{Sintoma atuais}

Julgamos pertinente trazer aqui, a título de ilustração dessa complicação paradoxal na relação entre vida e política, uma notícia de jornal com a qual Roberto Esposito abre sua obra intitulada Bíos: biopolítica e filosofia :

França, Novembro de 2000. Uma decisão do Supremo Tribunal de Justiça abre um conflito dilacerante na jurisprudência francesa, invertendo duas sentenças proferidas em recurso, que por sua vez contrariavam umas outras tantas decisões

\footnotetext{
${ }^{25}$ FOUCAULT, Michel. O sujeito e o poder. Op. cit. p. 132.
} 
emitidas em sentenças precedentes. Uma decisão que reconhece a uma criança, de nome Nicolas Perruche, nascido com graves lesões genéticas, o direito a interpor queixa contra o médico que não tinha devidamente diagnosticado a rubéola da mãe durante a gravidez, impedindo-a assim de abortar como era sua vontade expressa. O que aparece, nessa história, como objeto de controvérsia insolúvel no plano jurídico é a atribuição ao pequeno Nicolas do direito a não nascer. O que está em discussão não é tanto o erro comprovado do laboratório médico quanto o estatuto de sujeito de quem o contesta. Como pode um indivíduo recorrer juridicamente contra a própria circunstância - a do seu próprio nascimento - que lhe fornece subjetividade jurídica? A dificuldade é ao mesmo tempo de ordem lógica e ontológica. Se já é problemático que um ser possa invocar o seu direito ao próprio não nascer, ainda é mais difícil conceber que um não ser, como é o caso de quem ainda não nasceu, reclame o direito a continuar como tal e assim a não entrar na esfera do ser. O que parece impossível de decidir, em termos legais, é a relação entre realidade biológica e personalidade jurídica - entre vida natural e forma de vida. É certo que ao nascer naquelas condições a criança sofreu um dano. Mas quem, se não ele mesmo, teria podido decidir evitá-lo, eliminando antecipadamente o próprio ser sujeito de vida, a própria vida do sujeito? E não é só isso. Assim como a todo o direito subjetivo corresponde a obrigação de não o obstaculizar por parte de quem esteja em condições de o fazer, isto significa que a mãe teria sido forçada a abortar, prescindindo da sua liberdade de escolha. O direito do feto a não nascer configuraria, em suma, um dever preventivo, por parte de quem o concebeu, de o suprimir, instituindo assim uma cesura eugenética, legalmente reconhecida, entre uma vida julgada válida e uma outra, como se dizia na Alemanha nazi, "indigna de ser vivida" ${ }^{26}$.

O problema de Esposito será o da possibilidade de impedir a biopolítica de transformar-se numa tanatopolítica. Com o desenvolvimento da biotecnologia e da biomedicina, no século XXI a vida não mais está limitada às suas condições naturais,

\footnotetext{
${ }^{26}$ ESPOSITO, Roberto. Bíos: biopolítica e filosofia. Op. cit. p. 17-18. Itálico nosso.
} 
mas conta com o aparato técnico, intra ou extra-corpóreo, que não só otimiza e maximiza a vida qualitativamente, como projeta uma espécie de vida outra, híbrido de humano e máquina. Como afirma Nietzsche, a Cultura é tudo o que concorre para a correção da natureza ${ }^{27}$. No século XXI, poderíamos dizer que a Cultura não só corrige, como destrói e reconstrói formas de vida até pouco tempo relegadas aos romances de ficção científica, de modo que a biotecnologia, mais que correção, cria uma segunda natureza. Essa segunda natureza poderia ser o que Esposito chama de paradigma imunitário. A cultura seria justamente o ingrediente imunitário das sociedades ocidentais. E pensamos que Nietzsche não acha isso nada louvável, uma vez que para o mesmo o princípio de conservação não é sinal de força, e sim de esgotamento.

Em Bíos, biopolítica e filosofia, já no início (Op. cit., p. 23), Esposito afirma que Foucault não responde, ou ao menos não satisfatoriamente, ao grande paradoxo da biopolítica: como uma política da vida pode transformar-se numa política de morte. Talvez a resposta esteja naquele mesmo princípio, ou poder, característico da política moderna: "fazer viver e deixar morrer". De todas as maneiras, Foucault não se propunha a "responder" ou "dissolver" este paradoxo. Em nenhum momento o mesmo lança-se à proposta de uma "terapêutica" do presente. Limitava-se ao diagnóstico, o que já era uma grande empresa.

Decidimos intitular "sintomas atuais" a esta última seção do nosso trabalho porque, a nosso ver, antes de diagnosticar, é preciso ver os sintomas que poderiam constituir as marcas da biopolítica nos dias atuais. Sem dúvida, estes sintomas estão intimamente ligados ao desenvolvimento da biotecnologia e da biomedicina. A notícia de jornal que reproduzimos acima bem pode ser um exemplo destes sintomas. O malestar aparece aí sob a forma de aporia entre vida e direitos, por um lado, e ser e nãoser, por outro. Retomando a distinção entre bíos (forma de vida, vida inorgânica, cultural) e zoé (vida maquínica, orgânica, material), poderíamos dizer que estamos presenciando neste início de século XXI alguns desdobramentos do projeto neoliberal

\footnotetext{
${ }^{27}$ NIETZSCHE, Friedrich. Schopenhauer educador. In: Escritos sobre educação. Trad. Noéli Correia de Melo Sobrinho. Rio de Janeiro: PUC-Rio; São Paulo: Loyola. 2003. p. 157.
} 
que estimula a percepção do indivíduo como uma "empresa de si mesmo", o que explica a demanda cada vez maior por super-corpos sãos em super-mentes sãs, uma vez que um indivíduo "de bem com a vida "é uma empresa que rende mais. Nesse sentido, vemos um princípio econômico (rentabilidade) na base e na contração dos problemas concernentes à "bioética" e à "zooética" por assim dizer. Somos o que Michel Serres chama, em seu ensaio intitulado Petite Poucette ${ }^{28}$, mutantes, uma espécie que não se reconhece mais nas tradicionais classificações que distinguiam o natural do artificial, o humano do maquínico. Obviamente, com isto não queremos afirmar que até o século $X X$ as sociedades ocidentais adotavam um modo de vida que primava por uma relação exclusiva onde natureza e técnica se excluíam mutuamente, mas nos dias de hoje podemos reconhecer facilmente uma intensificação entre ambos em virtude justamente do fato de que na biopolítica do século XXI são os próprios indivíduos que veem a si mesmos em termos de biocapital, fomentando uma bioeconomia alicerçada na ideia de maximização ou otimização de si mesmo por meio de investimentos na investigação e desenvolvimento de aparatos tecnológicos no âmbito da biologia molecular. É com esta mesma consciência das transformações sociais decorrentes dos avanços tecnológicos que Esposito questiona a relação entre política e vida:

A política penetra diretamente na vida, mas entretanto a vida tornou-se outra coisa por si só. E então, se não existe uma vida natural que não seja, ao mesmo tempo, também técnica; se a relação a dois entre bíos e zoé deve agora, ou talvez desde sempre, incluir como terceiro termo correlativo, a techne, como supor uma relação exclusiva entre política e vida ${ }^{29}$ (ESPOSITO, 2010, p. 31).

\footnotetext{
28 SERRES, M. Petite Poucette. Les nouveaux défis de l'éducation. 2011. Acesso em 17/05/2017. Disponível em: http://www.academie-francaise.fr/petite-poucette-les-nouveaux-defis-de-leducation.

${ }^{29}$ ESPOSITO, Roberto. Bíos: biopolítica e filosofia. Op. cit. p. 31.
} 
Quando, em A Política da própria vida ${ }^{30}$, Nikolas Rose abstém-se de um julgamento em relação a casos como o que citamos acima, narrado por Esposito, quer dizer que o julgamento chegaria sempre atrasado. A multiplicidade de problemas que vêm surgindo diante da manipulação tecnológica da vida ocorre, atualmente, numa velocidade tal, que a disciplinarização e a normalização da mesma se encontra delegada a uma nova expertise concernente a uma infinidade de elementos que compõem a vida, e que não se reduzem mais ao controle da natalidade, da mortalidade e da morbidade, num esquema que separaria bíos e zoé (vida biológica inorgânica e vida zoológica - orgânica,) mas que invocam uma indiscernibilidade entre essas duas dimensões. Entretanto, a morada das forças vitais, permaneceria sendo o corpo de cada indivíduo, daí a ideia de uma ética somática - "ética não no sentido de princípios morais, mas, antes, como os valores para a conduta de uma vida -, que atribui um lugar central à existência corporal, física" ${ }^{31}$ :

estamos progressivamente chegando a nos relacionar a nós mesmos como indivíduos "somáticos", isto é, como seres cuja individualidade está, pelo menos em parte, fundamentada dentro de nossa existência carnal, corporal, e que expressamo-nos, julgamos e agimos sobre nós mesmos parcialmente na linguagem da biomedicina. Desde discursos oficiais sobre a promoção da saúde, passando por narrativas da experiência da doença e do sofrimento nos meios de comunicação, aos discursos populares sobre dieta e exercício, constatamos um crescente acento na reconstrução pessoal através da influência sobre o corpo em nome de uma boa saúde física que é simultaneamente corporal e psicológica. Exercício, vitaminas, tatuagens, piercing corporal, drogas, cirurgia plástica, redesignação sexual, transplante de órgão: a existência corpórea e a vitalidade do si mesmo tornaram-se o lugar privilegiado de experimento do si-mesmo. ${ }^{32}$.

\footnotetext{
${ }^{30}$ ROSE, Nikolas. A política da própria vida: biomedicina, poder e subjetividade no século XXI. Op. Cit. ${ }^{31}$ ROSE, Nikolas. A política da própria vida: biomedicina, poder e subjetividade no século XXI. Op. Cit.p. 19.

${ }^{32}$ ROSE, Nikolas. A política da própria vida: biomedicina, poder e subjetividade no século XXI. Op. Cit. p. 44.
} 
Entretanto, vale notar que o trabalho sobre si não pode ser confundido com um esforço narcisista de ordem estético-cosmética, mas, a nosso ver, o que está em cena, como bem observa Rose, é uma nova maneira de experimentação de si muito diferente da que havia no século passado, uma vez que toma a relação com o corpo como protagonista dos hábitos cotidianos. Nesse sentido, a ética somática apresentase como um sintoma dos tempos modernos: por um lado, a simples possibilidade de constituírem-se comissões para avaliar a vida ou a promoção ou a cessação da mesma pela lógica do "capital de giro" é, por si só, sintomática. Por outro, os conselhos de bioética seriam instâncias, não de julgamento dos dispositivos da biopolítica, ou da bio-economia, mas um registro flagrante do momento em que o corpo, enquanto instância ontológica que contempla as dimensões orgânica e inorgânica da vida, é campo para uma série de novos problemas que emergem não apenas nas instituições estatais, mas também no interior das instituições de investigação e experimentação sobre corpos humanos que envolvem vultosos investimentos nas indústrias alimentícia, farmacêutica, robótica, biologia molecular, cosmética, cirurgia plástica, ginástica, etc. Assim como a economia política, em seu contexto de nascimento, adota o mercado como princípio regulador da razão de Estado, a biopolítica, pelos aspectos assumidos no viés neoliberal, adota a ideia de vida como empresa como princípio da ação, não apenas governamental no seu viés estatal, mas de todo o projeto que tem por alvo maximizar a vida, nem que seja a custo de algum sacrifício da mesma, de modo que:

As múltiplas transações entre expertise e subjetividade, e as diversas injunções e desejos realizados de reformar e refazer nós mesmos através de intervenção calculada em nome de nossa autenticidade, autorrealização e liberdade, têm sido centrais para o "gerenciamento de si mesmo" em democracias liberais avançadas (Rose, 1989) ${ }^{33}$. O que é novo, talvez, é a centralidade concedida ao soma, à carne, aos órgãos, aos tecidos, às células, às sequências de genes e à corporeidade

\footnotetext{
${ }^{33}$ ROSE, Nikolas. Governing the soul: the shaping of the private self. Londres/Nova York: Rotledge, 1989.
} 
molecular para nossas maneiras individuais e coletivas de compreender e gerenciar nós mesmos como seres humanos ${ }^{34}$.

\section{4: Conclusão}

Conforme tentamos demonstrar na primeira parte do nosso estudo, e Deleuze o sintetiza numa frase (embora o mesmo não partilhe inteiramente desta ideia), para Foucault, "uma sociedade não se contradiz, ela se estratetiza, ou estratetiza." ${ }^{35}$. A ideia de paradigma imunitário passível de resultar numa tanapolítica, de Roberto Esposito e a de ética somática de Nikolas Rose podem ser vistas como sintomas característicos das sociedades ocidentais do século XXI, onde uma política da vida pode resultar no sacrifício de vidas, o que demanda uma nova maneira de pensar a ética, não mais pautada apenas numa psicologização, mas que agrega a noção de "individualidade somática" da qual resultam "formas emergentes de vida" regidas pelos valores da bioeconomia, onde investir em si mesmo é, antes de tudo, investir na maximização das potencialidades corporais e psíquicas por meio de intervenção técnica.

\footnotetext{
${ }^{34}$ ROSE, Nikolas. A política da própria vida: biomedicina, poder e subjetividade no século XXI. Op. Cit. p. 153-154.

${ }^{35}$ DELEUZE, Gilles. Desir et plaisir. Op. cit. p. 19.
} 


\section{Bibliografia}

DELEUZE, Gilles. Foucault. Trad. José Carlos Rodrigues. Lisboa: Vega(s/d).

DELEUZE, Gilles. Desir et plaisir. In: Magazine Litteraire, n. 325: Foucault aujourd'hui. Trad. Luiz B. Orlandi. 1994.

DREYFUS, Hubert. \& RABINOW, Paul. Michel Foucault: uma trajetória filosófica para além do estruturalismo e da hermenêutica. Trad. Vera Portocarrero. Rio de Janeiro: Forense Universitária. 1995. p. 158.

ESPOSITO, Roberto. Bíos: biopolítica e filosofia. Edições 70. 2010.

FOUCAULT, Michel. Qu'est-ce que la critique? suivi de La culture de soi. Paris: Vrin. 2015.

FOUCAULT, Michel. História da sexualidade I: A vontade de saber. Trad. Pedro Tamen. Lisboa: Relógio D'água. 1994

FOUCAULT, Michel. Em defesa da sociedade. Trad. Maria Ermantina Galvão. São Paulo: Martins Fontes. 1999. p. 287

FOUCAULT, Michel. O sujeito e o poder. In: MOTTA, M. (Org.). Ditos e escritos, Vol. IX: Genealogia da ética, subjetividade e sexualidade. Trad. Abner Chiquieri. Rio de Janeiro: Forense Universitária. 2014

FOUCAULT, Michel. Verdade e poder. In: MACHADO, R. (Org. e Trad.). Microfísica do poder. Rio de Janeiro: Edições Graal. 1979.

FOUCAULT, Michel. O nascimento da biopolítica. Trad. Pedro Elói Duarte. Lisboa: Edições 70. 2010.

NIETZSCHE, Friedrich. Schopenhauer educador. In: Escritos sobre educação. Trad. Noéli Correia de Melo Sobrinho. Rio de Janeiro: PUC-Rio; São Paulo: Loyola. 2003

REVEL, Judith. Diccionnaire Foucault. Paris: Ellipses 2008. p. 41). 
ROSE, Nikolas. Governing the soul: the shaping of the private self. Londres/Nova York: Rotledge, 1989.

ROSE, Nikolas. A política da própria vida: biomedicina, poder e subjetividade no século XXI. Trad. Paulo Ferreira Valerio. São Paulo: Paulus, 2013.

SERRES, Michel. Petite Poucette. Les nouveaux défis de l'éducation. 2011. Acesso em 17/05/2017. Disponível em: http://www.academie-francaise.fr/petite-poucette-lesnouveaux-defis-de-leducation 